\title{
Players and Puppetmasters: Alternate Reality Games and Negotiated Consumer/Producer Relationships
}

\author{
STEPHANIE JANES, Royal Holloway, University of London
}

\begin{abstract}
This article uses data gathered from interviews with game designers and a survey of a core group of 30 players to suggest that Alternate Reality Games (ARGs) allow media producers to develop a close relationship with consumers, prompting us to rethink previous notions of power in contemporary producer/consumer relationships. Discourse has moved from a resistant/incorporated dichotomy (Abercrombie and Longhurst 1998; Hills 2002) to the suggestion that fandom has become a normative mode of mainstream media consumption (Jenkins 2007). Theories of digital convergence and collective intelligence are often mobilised to argue for fans as empowered consumer collectives, increasing their ability to control decisions around their favoured media products (Jenkins 2006). Promotional ARGs are unique sites for studying this complex relationship. ARGs have been used since around 2001 to promote a number of films including A.I.: Artificial Intelligence (Steven Spielberg, 2001) and The Dark Knight (Christopher Nolan, 2008). They create a narrative mystery set in the world of the film which is broken down and scattered across the internet. Players work collaboratively in online fan communities to reconstruct that narrative using everyday media channels such as email, websites, phone calls, voicemails, and larger scale live events, like scavenger hunts. Such games are sites of real-time interaction creating a give/take relationship between producers and consumers, which results in a more complex system of cocreation and negotiated ownership, as opposed to resistance, incorporation, or indeed cultural empowerment.
\end{abstract}

\section{KEYWORDS}

Alternate Reality Games, consumers, producers, ownership, agency, empowerment.

\section{Introduction}

Alternate Reality Games (ARGs) have been used by media corporations for around ten years as part of promotional campaigns for Hollywood films. The first ARG used to promote a film was part of the marketing strategy for A.I: Artificial Intelligence (Steven Spielberg, 2001). Named The Beast by its Microsoft creators, it lasted for 3 months prior to the film's release and attracted large numbers of players, around 7,000 of whom formed the online player community known as the Cloudmakers. Since The Beast, films such as Cloverfield (Matt Reeves, 2008), The Dark Knight (Christopher Nolan, 2008), and Super 8 (J. J. Abrams, 2010) have all launched ARGs as part of their marketing campaigns. Promotional ARGs are rarely created in-house by media conglomerates. Instead, a company specialising in immersive or interactive online marketing is usually contracted to produce the game itself, with the studio having as much or as little input as it wishes, usually the latter. This creates an unusual state of affairs, in that players develop a relationship not with, say, Paramount or Warner Brothers, but with smaller, boutique marketing companies such as 42 Entertainment. 
Promotional ARGs are unique in that they are explicitly commercial entities, while at the same time encouraging - and arguably requiring - a mode of engagement which replicates that of a 'grassroots' fan community. Feelings of player agency are created via interactivity, but are arguably illusory since game designers (or puppetmasters (PMs) as they are known on player forums), ultimately control the strings of the games they have designed. So, in a situation where an apparently organic fan community can be created by a media conglomerate, how can this particular fan community control the production of meaning around the fan text? Surely participation in such an environment can never really occur outside of the domain of the preferred readings of producers. Furthermore, how relevant is that kind of textual or cultural power relationship to such media consumers, if they are willing to collude with producers for the illusion of inclusion?

In order to examine the relationship between PM and player, I surveyed a small group of around 30 core ARG players, most of whom were based at ARG forum unfiction.com and asked them to agree or disagree to a number of statements regarding control and ownership of ARGs. Participants were primarily selected from this forum as it forms the largest and most well-established hub of active ARG players (33,454 registered users as of January 2014). Surveys were comprised of both the 'agree/disagree' statements and open text boxes below these statements. The aim of this was primarily to engage participants quickly before asking them to provide further, more in-depth qualitative responses. This proved effective as most participants chose to provide a more detailed response to these survey questions. Interviews were also conducted with a number of PMs including Sean Stewart, co-founder of 42 Entertainment and Lead Writer on The Beast, and Adrian Hon, CEO of games development company SixToStart and a former Cloudmaker. PM and player perspectives are also taken from transcripts of ARG-Fest 2007, an annual conference which has historically provided an open forum for discussion between PMs and players.

After offering a brief definition of ARGs and an overview of previous theorisations of the relationship between fan communities and media producers, this article will go on to outline some of the ways in which ARGs can provoke feelings of ownership without necessarily offering up authorial control. It will then discuss the manner in which both players and PMs negotiate the commercial status of promotional ARGs as creative works inevitably bound up with systems of consumer capitalism. Finally, it will question whether ARG communities can exist comfortably within that system on their own terms, or whether an alternative system of negotiation is at play.

\section{Defining ARGs}

A common misconception is that ARGs are console games that tie in with films, virtual worlds like Second Life (Linden Lab, 2003), or massively multiplayer online role playing games like World of Warcraft (Blizzard Entertainment, 2001). While they are none of these it is actually quite difficult to define them precisely. In their most basic form ARGs are interactive, immersive narratives. A more thorough definition might be:

Campaigns which create immersive, interactive narratives by using a range of communication technologies and delivery channels. ARG narratives are often fragmented, and must be re-assembled through the collaborative effort of players, who may be asked to solve puzzles, crack codes, or participate in on- and offline activities to progress. (Phillips 2005) 
As promotional materials, ARGs function to create buzz around a given product. The most notable and complex promotional ARGs have often spawned from narrative-based products such as films, videogames like Halo 2 (Microsoft Games, 2004) and more concep-based music albums like the Nine Inch Nails' Year Zero. In the case of ARGs for films, they offer more immersive engagement with the film's extended narrative. They usually set up a mysterious storyline, set in the world of the film, involving events that occur chronologically before or after the film's narrative. Puzzles are deliberately designed to be too complex for one person to complete; they require collaborative work. As a result, online communities form around the games, often in forums like unfiction.com, where players can discuss the unfolding narrative and work on puzzles together. As the narrative progresses, players can contact characters and companies in the game in various ways including email, telephone, and post. In-game characters can contact players in the same way. In many cases the games are structured in such a way that that to solve the mystery, you have to go to see the film. This is particularly true of Cloverfield and Super 8, where the game offers hints and clues, which lead up specifically to the film's revelation of a monster, alluded to but never specifically shown in their respective teaser trailers.

There are also a number of rules to the gameplay which have mostly been developed by players over the years. For example, players and PMs generally agree to adhere to the 'This Is Not A Game' aesthetic, referred to as 'TINAG', whereby the game never actually acknowledges itself as a game (Thompson 2005). Websites must be convincingly real, phone numbers must actually work, and characters are referred to as if they exist in real life. PMs are not to participate in forum conversations regarding their games, either as themselves, under pseudonyms or as characters, until the game has come to a conclusion. The emphasis on strict adherence to these has shifted as the genre has evolved, particularly with regards to TINAG, which becomes difficult to maintain successfully. However, they remain defining principles underpinning the philosophy of the games.

ARGs play out in real time over anything between 3-18 months before release. This results in a rather unique relationship developing between players and PMs, in that PMs often find themselves having to respond in real-time to players' actions, or indeed inaction, in order to keep the game on track. This can lead to producers having to make sudden adjustments to puzzles, characters and narrative or plot details. During The Beast, for example, the character Red King was created as a response to player interest in what was meant to be a minor character (Stewart quoted in Cloudmakers 2001). ${ }^{1}$ PMs were also forced to create an entire sub-plot revolving around a character and her A.I. doppelganger, because players spotted a piece of stock photography which had been used twice by the designers (Puppetmaster FAQ 2001). During the games, PMs monitor forums constantly in order to keep track of player activity. In earlier games, including The Beast, PMs came out from behind the curtain by contacting players directly, and often held live online chats with players afterwards. These were open and honest discussions about what went wrong, what could have been improved and what players found most enjoyable about the game. This practice has declined but surveyed players did mention being asked for post-game feedback.

In my interviews both players and PMs attested to ARGs' ability to offer the opportunity for intense fan/producer interactions. Both parties described this relationship definitively in terms of collaboration, co-operation and a kind of give/take experience that can become quite personal. Common metaphors for this interaction included:

\footnotetext{
1 'Off the top of my head, Red King is an example of simply being FORCED to create a character by player interest; and then given the seed idea for that character by player copyediting' (Stewart quoted in Cloudmakers 2001).
} 
a bit like a tango. So you propose a step and the lady either accepts or chooses not to accept the step. When you're running these things, you're leading but it's definitely a two-person interaction. (Stewart, personal interview, 2012)

Like jazz musicians, playing off each other. NOT like two chess players playing against each other. (Player Survey 2013)

Performer and audience... but in both directions. (Player Survey 2013)

Such close interactions between media producers and consumers do not resonate strongly with how this relationship has previously been conceptualised.

\section{Fan Resistance/Incorporation}

Discussions surrounding the extent to which fan communities 'resist' or remain in thrall to the power and influence of media producers, structure a great deal of recent fan studies. Scholars have generally come down on one side or the other, creating what Nicholas Abercrombie and Brian Longhurst have described as a 'resistant/incorporated dichotomy' $(1998,15)$ with fans being either empowered, active consumers or passive dupes, when in fact these relationships are far more complicated.

These arguments are also rooted in cultural studies discourse regarding the influence of mass media, most notably work carried out at the Birmingham Centre for Contemporary Cultural Studies in the 1970s by Stuart Hall et al. (Hall 1973; Hall and Jefferson 1976; Hall et al. 1978). Many of these studies focussed on the idea that subcultures were creating alternative identities using the cultural symbols available to them, subverting their intended meanings to create oppositional cultures (Hebdige 1979). However, Halls' influential encoding/decoding model highlights the limits of this textual politics. It maintains a level at which power structures influence interpretation, suggesting that codification is always unavoidably 'structured in dominance'. There always exists a domain of preferred readings which have 'the institutional/political/ideological order imprinted in them and have themselves become institutionalised' (Hall 2007 [1973], 513). A more extreme view is reflected in Louis Althusser's theory of mass culture, which argues that the mass media is part of an ideological structure which can only work to reproduce dominant ideologies. This system is so involved with the very creation of the subject, that the subject can never truly form any kind of resistance to that ideology (in this instance, consumer capitalism) (Althusser 2008).

Henry Jenkins' early work builds upon this, attempting to empower fandom as a response to what he saw as the demonization of fans, by both mainstream media and academia, as obsessive, antisocial 'nerds', desperate to own any commodity related to their chosen fan text (Jenkins 1992). Focusing on media fandom's capacity for cultural production, he rejects Hall's theory as being too rigid. Instead he uses Michel De Certeau's ideas of 'poaching' (de Certeau 1984, 229), emphasising 'the process of making meaning and the fluidity of popular interpretation' (Jenkins 1992, 34). By repeatedly claiming ownership of 'their' texts, and actively utilising their images and characters in practices such as fan fiction, fans are depicted as resisting the power structures of the media industry, which expects a mass audience to passively consume its products. Jenkins' later work continues this relatively optimistic stance on the evolving relationship between consumers and media producers in the age of digital convergence (Jenkins 2006a). ${ }^{2}$ As consumption becomes a

\footnotetext{
${ }^{2}$ See also (Levy 1997) whose notion of 'collective intelligence' informs much of Jenkins' work.
} 
more collective, social process, Jenkins argues, consumers form 'knowledge communities' around texts. Fans participate in 'collective intelligence', which can be seen as 'an alternative source of media power' (Jenkins 2006a, 4). The internet is crucial in forming this participatory culture. By pooling knowledge, groups can draw from a huge range of expertise, and because information is shared and valued equally within the knowledge community, it 'destabilises attempts to establish a scriptural economy in which some meanings are more valuable than others' (Jenkins 1992, 140).

But this vision of the grassroots fan organisation against the might of the corporate machine risks telling only one side of a complex story. Fans depend on the media industry to produce the very texts they love. Furthermore, they may be reliant upon 'average' viewers (that is, the wider 'nonfan' mass audience) to keep the property popular enough that producers deem it worth continuing. It could be argued that notions of fan agency and resistance were overly celebratory and that fans actually exist as negotiated parts of the system.

Fan studies has increasingly tried to move away from this 'resistant/incorporated' dichotomy of consumer/producer relationships. According to Simone Murray, this particular binary view left cultural studies unable to adequately cope with instances where fan communities form 'uneasy joint ventures' with multi-national conglomerates. If media producers are working with fans, there is nothing left for them to 'resist'. As Murray puts it, 'poaching can only count as such if there is a gamekeeping regime for it to flout' (Murray 2004, 12). Internet technologies have now brought the two groups closer and made them more visible to each other. Moreover, they have created a sea of 'user generated content', causing the boundaries between consumer and producer to blur. And yet the distinction lingers. Jenkins' most recent publication continues to call for a more nuanced understanding of 'the reality of power relations between companies and their audiences' (Jenkins, Ford and Green 2013, 164). As companies start to elicit "participation" from their audiences he warns against a 'blanket celebration of participation' (Jenkins et al. 2013, 164) when the reality is, and indeed always was, more complicated.

ARGs provide an excellent space for examining this relationship as they offer a site of near-real time interaction between media producers and the audiences they court. Between this and the fact that players have helped define some of the rules of engagement in this niche form of gaming, it would seem that there is a fairly give/take relationship developing between media consumers and producers which suggests not resistance or incorporation but co-operation and indeed sometimes co-creation. However, it is necessary to question more closely the levels of agency actually offered by ARGs.

\section{The Illusion of Inclusion}

Active audiences and player agency are at the forefront of discussion around ARGs. They are depicted as both an attraction for audiences and something that corporate clients fear. Either way, active audience participation is frequently cited as a defining element of the genre:

An ARG is a story or journey involving a diverse selection of both online and offline activities, driven by an online community whose interaction and experience determines the journey and often the ending. (Goldie 2008) 
The narrative is shaped - and ultimately owned - by the audience in ways that other forms of storytelling cannot match. No longer passive consumers, the players live out the story. (Rose 2007)

In early ARGs, player could indeed potentially affect the game narrative via their actions/inactions:

Players drove the story more than the puzzle building [...] Players spotting typos were responsible for two entire characters. Players also voted with their interests. The Red King [...] wasn't supposed to be mentioned past the first week. But the web developers threw in a cool sound file, the players reacted, and a star was born! That wonderfully dynamic interplay is entirely due to the players. (Puppetmaster FAQ 2001)

When discussing the design and implementation of ilovebees, the ARG promoting the video game Halo 2 in 2007, Community Lead Jane McGonigal goes as far as to suggest that 'the designers, through ambiguity, must cede control over the final scope and dimensions of the game's solution to the players' (McGonigal 2008, 215).

However, many producers believe players do not necessarily have as much control over the game as they might think. PMs can always take steps to limit the number of possible options a player has by more heavily directing the game. Should players attempt to take the game in an unwanted direction, PMs have the capability to override this and bring the game back to the original plan, or at least somewhere closer to it. Brian Clark, CEO of media lab company GMD Studios, suggests:

Players think they have a lot of control, but really, what you even choose to acknowledge or not to acknowledge makes a huge difference in how that plays out. (ARGFest Transcript 04 2007)

In one post-game chat a player asked Sean Stewart and Lead Designer Elan Lee whether speculation on the forums influence any of the puzzle design. The response suggests players were sometimes reading responsiveness in The Beast which was in fact coincidental:

Stewart - Convergent evolution. I imagine you're most [sic] talking about Enigma [...] which is, after all, at this time the most famous code in the history of the world, and thus a pretty likely thing to come up in the game.

Lee - I was locked away in a closet for the entirety of the game. Sean would tell me about really great ideas every once in a while, but many of the puzzles just happened to be along similar lines to what you guys were thinking about. (Cloudmakers 2001)

The Beast had set the bar for player agency very high and it was not possible to sustain that in the long term due to the sheer amount of labour involved in monitoring and responding to the community at that speed. As levels of interactivity were slowly lowered in subsequent ARGs, the two parties had to develop a balance of power and expectations in their relationship. Players had to trust PMs to control the game to a certain extent in order to make sure it did not spiral out of control, but they also had to feel assured that PMs would be responsive and not try to dictate player actions too strongly. Jaclyn Kerr, Administrator at unficton.com and Assistant Editor at ARGNet, puts this neatly in a sporting analogy: 
You can get PMs that will almost try to direct the story and [...] you can almost see the players rail against it and when they start to rail against it they start losing their trust in the PM's ability to react to the situation. There is a give and take in the creation and the development and the actual playing of the ARG. The PMs are throwing out content and the players are picking it up and throwing it all back. It's very much like a tennis match. And when that PM team, instead of playing like they normally would, instead of hitting the tennis ball back they hit a bowling ball, it doesn't make sense [...]. If you can't hit the ball back within the court area then the players can't play your game. (ARGFest Transcript 04 2007)

Sean Stewart rejects what he describes as a 'choose your own adventure' model, whereby players make various choices throughout the narrative which send it in a particular direction. He highlights the difference between 'a story that the audience gets to change [which] is usually a bad idea and is usually a bad story' and 'a story that the audience gets to co-create [which] can be a very good story and very engaging experience' (Stewart, personal interview, 2012). Fundamentally, he believes the 'choose your own adventure' model breaks the basic unspoken agreement made at the start of any story that 'you agree to act as if these people and real and that their lives really matter'. As soon as a 'choose your own adventure' story asks you to make a choice about the next part of the story, it says 'this isn't something that happens to real people, this is a game that you and I are playing' (Stewart, personal interview 2012). Disbelief is unsuspended at various moments throughout the game and disrupts the experience.

As an alternative, Stewart claims ARGs offer 'the chance to affect or be seen, or be reflected in the narrative' rather than to be actively controlling that narrative. 'In ARGs I've created a lot of different ways for people to see themselves in the story and register their impact in the story' (Stewart, personal interview, 2012). This is exemplified strongly in one element of The Beast which saw players build a database of their own nightmares, in reaction to the character of Loki, an A.I. who consumed dreams. Stewart then wrote a soliloquy for that character based on the information in the database and the developers created a flash movie with a voiceover within 36 hours of the database appearing. He then recalls "watching people say "Oh my god" then say "wait a minute, that's me"" (Stewart, personal interview, 2012). In this way, instead of 'controlling' the story, he suggests the story is 'responsive, the story acknowledges the audience's involvement. All those things feel really good and give that sense of ownership but don't take you down that cul-de-sac of controlling events' (Stewart, personal interview, 2012).

Other elements of ARGs are likely to provoke feelings of ownership and emotional or personal if not textual empowerment in players, without them having such a direct impact on the narrative of the game itself. The relationship between players and PMs can have this effect. It's a 'call-and response, jazz style interaction... It increases the ownership of the players in the game enormously' (Stewart, quoted in McGonigal 2008, 216). The mere fact that PMs respond to players at all (whether this makes any manifest difference to the game's trajectory or not) suggests what they say and do is important and could potentially make a difference.

Feelings of empowerment could also come about via player interactions within the community, and the collaborative nature of the games rather than between PMs and players: 
Reading a book or watching a TV show can be a very singular intimate experience and creating an ARG, and creating a community around that is very much empowering the players to share that intimate experience with 10,000 of their not so closest friends. It's an empowerment, you get that incentive and the ability and drive to share that information. (Kerr, quoted in ARGFest Transcript 04 2007)

McGonigal also argues that the collaborative nature of the communities is fundamentally inclusive, offering a chance for everyone to feel like they have contributed to the group's success:

The plausibility of so many diverse interpretations empowered players of all skill levels, natural abilities, inclinations and interest to achieve success [...]. It ensures that no player is left out of the game, no individual discouraged or excluded from the opportunity to contribute to participatory culture. (McGonigal 2008, 215)

Additionally, ARGs can provide an empowering sense of discovery for players:

That sense of discovery is so important for ARGs because if, instead of shouting, instead of pushing our message at people, if we whisper it, if we just embed a small flash of imagery in a TV commercial, if we do something subtle, it could be so much more powerful [...]. You, who discovers [sic] that bizarre frame that's out of place on the TV, suddenly you own that experience. It's yours. You feel this tremendous sense of pride because you found it. And you're so much more encouraged to tell your friends about this, because it isn't something someone threw at you. This is something you pulled. (Lee quoted in Ruberg 2006)

McGonigal also notes the plethora of player-created artefacts and networks without which the games are impossible to play:

Wikis, group-moderated blogs and multi authored mailing lists, collaborative spreadsheets to list-servs, and toll free online teleconferencing systems. (McGonigal 2008, 207)

In this way, players arguably create not only content but the systems to distribute and discuss that content. ARG designer and researcher Christy Dena also estimates that players spend more time interacting with these resources than they do with 'official' game content (Dena 2008).

Gamejacking (creating false websites which appear to be in-game) could even be considered as a form of user-generated content (UGC). Some producers view it as a communication from players that there are gaps in the game which PMs need to deal with (Evan Jones quoted in ARGFest Transcript 03 2007). Although it could ultimately be disruptive to the game, any form of UGC would certainly contribute to a sense of shared authorship and therefore ownership of the game.

Some player comments support an argument that it is these elements, rather than any form of influence over the story that really develops feelings of ownership of the text. As one player put it, for example, 'I don't think it's the ability (actual or perceived) to influence the story that gives ownership, as much as the give-and-take, call-and-response mechanic, along with the feeling of community' (Player Survey 2013).

At the conclusion of ilovebees 'gamers were genuinely surprised to hear the design team say the gamers themselves had control over how the plot unfolded' (Kim et al. 2008, 40). If players are unaware of their impact on plot development, is it fair to say that this is genuinely part of the appeal to these games, or that players derive pleasure from it? ARG producer and player Adrian Hon addresses this directly in his walkthrough guide to The Beast: 
People want to be entertained in games like this, they don't want to have to make decisions. (Hon 2001)

If players are constantly overwhelmed with endless options then it actually takes away from some of the enjoyment and places a strain on producers, who have to provide content for every eventuality.

72 per cent of surveyed players agreed that the ability to affect the outcome of an ARG was one of the genre's main attractions. As communities have become more knowledgeable about the games and their construction, it might be the case that this varies with different communities or even different individuals. Players of ilovebees may have been new to the genre, but players of The Beast, would have been more aware of their role in creating the storyline. There was also a general consensus that not only was there a 'sense' of ownership over the game, but that players could also have real ownership (i.e. authorial control or at least influence) of an ARG. Yet a similar number of participants agreed that PMs were ultimately in control of the game and its outcomes.

McGonigal's analysis of the player/PM relationship sheds some light on these apparently contradictory results. There has to be a level of control exerted by PMs, or the game becomes unplayable. If the trust relationship does break down, and players refuse to perform, the game breaks down too, and players are

denied the opportunity to play [...]. There is simply no optionality to the power play do exactly what you're told, or there's no play for you. This underlying power structure requires a level of overt submission from gamers that is simply unprecedented in game culture. And so the players' definition acknowledges: It is the puppetmasters, not the players, who 'control the game'. (McGonigal 2007)

This powerlessness, she continues, is pleasurable for players and is definitely wilful.

For players, the pleasures and challenges of real world gaming missions are the pleasures and challenges of dramatic performance. And for puppetmasters, writing real world mission scripts is very much the same process as writing dramatic texts, redesigning them in real time is very much the process of directing live actors on stage. (McGonigal 2007)

Although the term 'submission' is rather strong, it does seem that players enter into the games having acknowledged that in order to play the game, and to experience the 'sense' of ownership of the text, they must accept that PMs ultimately control the text. To use McGonigal's dramatic analogy, an actor may offer interpretations for a performance, but it is the director who determines wither that interpretation is valid for their vision of the text.

An alternative view is that it is not whether fans actually have power that is important, but whether they believe they have it, and how important this belief is to them. Natasha Whiteman's study of identity in online fan communities indicates that fan identity is constructed around ideals of agency and the ability to collectively save or change the media products they care about. The commercialisation of these texts is still a sore point for many fans, but it is possible that as long as they feel a sense of participation. For some ARG players, this experience is more important than having the power to actually shape the game and some player comments do support that argument. 
One player puts it plainly: 'It's the illusion of control, not necessarily the control itself' that is the attraction (Player Survey 2013).

Stewart also comments on these 'illusory' feelings remarking: 'I think I have, without exaggeration; single-handedly invented more ways for the audience to feel the illusion of control, than anyone in the world' (Stewart, personal interview, 2012). However, he finds the term 'illusion' overly pejorative, although it is strikingly difficult to find a suitable alternative. This resonates strongly with the ethical stance that many PMs take on their relationships with players. There must be a level of trust, and if there is the suggestion that players are being 'hoaxed' or tricked in any way then that trust breaks down and the games become unplayable. However, it does seem that a number of players actively and knowingly opt into that 'illusion', willing to cede a level of narrative control in return for a well-constructed and genuinely engaging entertainment experience. As the game has evolved, players have become more knowledgeable about the games and how they work. Indeed, many of the core players have played the role of PM themselves, either professionally or as part of a grassroots game. 'Illusion' has connotations of players being somehow fooled or hoodwinked, but players choose to buy into the pleasures of that 'illusion' because they know that the alternative is likely to end in a far less enjoyable gaming experience. PMs, for their part, agree to provide those illusions via a responsive game design which respects that choice by not making them feel like they are being overly manipulated.

This relationship simply does not fit the resistant/incorporated dichotomy, but nor does it automatically equate to consumer empowerment or control. An ARG develops something of a contract between players and producers, which, if broken, breaks the text itself. In this respect, cocreation and co-operation definitely underpin ARGs in some way, because players and PMs to have to keep their sides of the bargain in order to achieve what is in fact a common goal: an entertaining and immersive gaming experience. Such levels of co-operations and even co-dependency in such a highly commercial, promotional context might prove problematic for fan communities, who continue to negotiate their position with such a media environment.

\section{Negotiating Commercialism}

Promotional ARGs create or encourage the formation of what looks like a grassroots fan community within an explicitly commercial context. According to Jenkins, fan communities are by definition, self -created (Jenkins 2006b, 137). So what happens if fandoms are corporate creations rather than organically formed communities? Although it appears that ARG communities piece together these narratives themselves, they do so with information fed to them by Puppetmasters, and they ultimately arrive at a corporate-sanctioned conclusion. These strategies construct the space and conditions for fandom to occur whilst utilising it as part of a wider marketing exercise.

This conflicts with traditional conceptions of fandom as resistant or oppositional to the commercialism of media corporations. Matt Hills argues that fans occupy a middle ground, whereby they may hold anti-commercial ideologies, but continue to display commodity-completist practices (Hills 2002, 28). He argues that this is a lived contradiction for any fan, and rather than try to close it down, theoretical approaches to fandom must be able to accommodate it. Fans are therefore aware of their position and value within the commercial media industry and constantly 
negotiate that position. They are thereby capable of existing within the system that they apparently oppose (Hills 2002, 28-35).

A similar sense of negotiation is apparent in survey responses. Players are overwhelmingly aware they are part of a promotional exercise. Yet few respondents suggested that this would deter them from playing a game. It seemed it was more important that the game be entertaining and engaging, whether it is promotional or not. This suggests that, to further Hills' argument, not only do fans consciously occupy this middle ground, they might do so increasingly without finding this position problematic.

However, while their status as marketing was accepted, some players drew a firm line between this kind of ARG and a fan-created or grassroots ARG. As one player summed it up:

These days a movie promotional game is rarely a true ARG in the traditional sense, and the relationship to the audience differs from the kind of engagement players feel with smaller ARGs run for the sake of its own story-telling model. (Player Survey 2013)

They also expressed reservations about being used as part of a marketing campaign, particularly if the game did not offer the level of involvement they were looking for, or expected from ARGs. This emerged strongly in several responses:

If there is no connection [between the game and the film], it makes me feel like one of many sheep in a marketing campaign. In most cases, I feel like I've been involved even an asset - to the product's campaign, when the ARG and filmic stories are connected and my enthusiasm shows. (Player Survey 2013)

I don't like to feel like a marketing tool, but rather as a participant in the game/marketing technique. (Player Survey 2013)

With Super 8, it ultimately felt like we were being force-fed information and promo materials. We had to find the ways to access materials, but then it was just a waiting game for the PMs to update. (Player Survey 2013)

There seemed to be a perception that promotional ARGs don't or can't offer the same kind of engagement and are therefore not 'real' ARGs, because this relationship, for both players and game producers, is integral to the genre as they understand it. Some expressed an issue around agency specifically within promotional ARGs as opposed to grassroots games

because these ARGs are much less likely to bend to the will of players or give players a sense that the choices they make have any sort of impact since the final product (be it a TV show or movie or whatever) already exists. The decisions players make can't impact that product. (Player Survey 2013)

Despite this misgiving, almost all the respondents who agreed that players felt a sense of ownership over a game, also agreed that this could extend to the films being promoted. It is, of course, unlikely that players influence, for example, the kind of Batman film Christopher Nolan decides to make by playing an ARG, but some evidently feel that participating in the game makes them feel like that film belongs to them, in some way.

However, players evidently recognise that promotional ARGs are likely to have a more limited level of agency and participation involved. The perception is that ARGs can and should offer high levels of player agency, but that they do not, or cannot in a promotional context. When this 
happens, players are more likely to start drawing on such discourses of authenticity, and brand the game 'just marketing' or 'just another viral'. Discussion regarding Super 8 in particular involved a lot of debate as to whether certain online content was in-game and therefore 'for us', or whether it was 'just viral material', intended for a wider, uninitiated audience. This reflects another dualism which Hills identifies and critiques, as fan communities often construct themselves against 'mindless (or undiscriminating) consumers', distancing themselves from the more commercial elements of their fan activity (Hills 2002, 21).

Jenkins has talked previously, in rather sombre tones, of the 'mainstreaming' of fandom, even of the death of fandom. Participation in the ARG could be seen as a way of reinstating something of the subcultural to a property which, for many fans, might have lost that element. ${ }^{3}$ Whether this is an intention of media conglomerates is currently unclear, but this kind of discussion on forums certainly suggests that some fans may be actively trying to regain something of that status, rescuing a once niche property from the mainstream.

This all points to a situation where these fans do not exist quite as comfortably within the system of commerciality and commodification as it would first appear, and their rejection of that which is deemed 'just marketing' is heightened by the perception of ARGs as a genre in which a game is simply not valid unless it offers a genuine exchange between consumers and producers. What changes this dynamic quite dramatically is that producers can also be seen to display similar attitudes to the commercial nature of the games they themselves produce.

In an eloquent quote, musician Trent Reznor proclaimed that the ARG used to promote the album Year Zero for his band Nine Inch Nails was 'not fucking marketing' (Reznor in Rose 2007).

Adamant that he was 'not trying to sell anything', he made a point of paying for the game out of his own recording budget (Rose 2007). This highlights a struggle to define promotional ARGs as not 'just' marketing, but as something creatively valuable in its own right.

Some quotes, including Reznor's simply deny the marketing element of ARGs. Other discourses elevate and emphasise their other, more worthy functions. This does not necessarily mean that their value as marketing is negated entirely, rather that the games are frequently discussed by their creators in other contexts. For example, there is a tendency to discuss ARGs as 'cultural events' rather than 'events marketing':

The Dark Knight's multi-faceted promo push transcends marketing to exist as cultural event. This is looked upon as viral marketing but you have to look at it as an engrossing experience. (Jonathan Waites quoted in Lee 2008)

McGonigal's work refers to ARGs as vehicles for promoting social and cultural change through collective intelligence (see McGonigal 2007 and McGonigal 2011). Most often, ARGs are discussed by their creators as an art and a craft, and therefore comparable to other narrative-based artforms such as film or literature. Game designers identify as 'artists and ARGs as an artform' (Stewart in ARGFest Transcript 05 2007). They are presented as creative storytellers rather than marketers or business people. The games' function as marketing is incidental - the financial means to a creative end.

\footnotetext{
${ }^{3}$ The Batman franchise is a potential example of this.
} 
Producers also frequently express the desire to create ARGs outside of marketing budgets, in order to obtain greater creative and financial independence:

Our dream is, of course, that we want our own intellectual property and we want to promote our own ideas, and we want to create something start to finish that does not support another property. (Lee in Siegel 2006)

Conversely, they also clearly understand the games will always have to be profitable and therefore will always have some sort of commercial existence: as Lee puts it, 'You've got to make money somehow' (Lee in Ruberg 2006). ARGs may have been born in a commercial environment, but after a while many producers were keen to move them out of that arena. As much as players of promotional ARGs negotiate and almost justify their interactions within this overtly commercial space, producers also seek to define ARGs in terms that are categorically un-commercial and to move them away from that space where possible. They appear to equally caught in the trappings of commercial media and struggle in similar ways to define themselves within it. However, the problem is further complicated for players, because they not only have to negotiate the commercial nature of the game, the game can arguably be seen to commodify the fan experience itself.

\section{On Their Own Terms?}

Hills continues by arguing that a media text's economic value is significantly changed by the fans' appropriation of the text, using Marxist notions of use value and exchange value (Hills 2002, 3235). The text remains a commodity in the sense of the 'economy proper', but its reclamation by fans creates a new exchange value 'through a process of localised use-valuations which are not entirely reducible to economic models' (Hills 2002, 35). The monetary value of a Batman comic is based on a value system held by fans alone. It has more to do with the values of the community as a whole, or indeed of an individual fan, than its actual economic value. For Hills this means the marketplace 'is underpinned by lived experiences of fandom' (Hills 2002, 35). This augmented version of economics means that although fans are 'complicit' with consumerism, they are in a sense involved in it on their own terms. 'Power' or 'control' within this system cannot necessarily be located in one group or another.

In some senses, the ARG experience fits this model. For example, during The Beast, players did ultimately cause changes in the narrative and the resulting game was very different than how PMs had intended:

Our original plan for the game was quite different from the final product, which was written on the fly (in between marathon bug fixing-sessions and orange juice binging). That wonderfully dynamic interplay is entirely due to the players. (Puppetmaster FAQ 2001)

Players therefore had an understanding of the film not purely shaped by marketers, but by their lived experiences of the game and the direction in which they and the player community took it. Furthermore, the rules of the game, including conditions of play for PMs, were developed by players, rather than producers, suggesting that on some level, players are indeed involved with consumer capitalism on their own terms.

But what happens when systems which belong to the 'economy proper' offer a pre-packaged and designed 'lived experience of fandom'? ARGs encourage and promote fan-like activity around a property, essentially offering a constructed fan experience. The experience itself is commodified, 
thus regressing towards back towards 'exchange value' and becoming a commodity in itself. It could be argued that power is therefore sliding back into the hands of media producers, as they manufacture a fan experience which provides all the pleasures of participation, but is arguably structured according to corporate need to control online buzz and brand identity rather than handing any real power over to consumers to shape the product. Can players really be involved in this system on their own terms?

\section{Conclusion: Negotiated Ownership}

ARGs create a close relationship between players and PMs, which appears to offer high levels of agency and ownership of the text for players. Player agency was promoted heavily as one of the main attractions of the games in their early days. On closer inspection, this is in fact a negotiated level of ownership, one in which both parties engage to keep the game running smoothly whilst still being able to offer the feelings of involvement and participation that players have come to expect from the games. Such feelings can be prompted by elements of ARGs which do not necessarily give players direct control or influence over the game itself, and indeed to offer up such a level of authority to consumers is likely to derail the game entirely. For their part, players seem to understand this and are willing to enter into the relationship in the knowledge that PMs may ultimately make decisions about where the narrative goes. In this article, I have been concerned with how this delicate two-way interaction complicates certain assumptions of fan studies theory.

In a promotional ARG, that level of interaction is often more limited, and players do seem to feel the need to negotiate the commercial status of these games in a manner similar to that described by Hills. However, when producers themselves also struggle with the commercial nature of their games, the battle-lines suddenly become very differently drawn, and the two parties would appear to identify with each other much more strongly. They share similar goals: to distance the genre from its commercial origins where possible. On the other hand, such arguments for co-operation and cocreation in this relationship become harder to hold when one considers the wider implications of ARGs as constructed fan experience.

Ultimately, this relationship is complex, and in its complexity cannot fit easily into current theories surrounding fan communities and media producers. However, it does challenge these theories and asks us to reconsider what contemporary media fans actually want from producers. 'Ownership' or authorial control of a media text may not necessarily be a goal we can always ascribe to media fans. It is entirely possible that this particular group of fans, unable to truly control or construct their fan text, view the ability to participate in it via a well-constructed and genuinely engaging promotional ARG an acceptable alternative.

\section{References}

Abercrombie, N. and Longhurst, B. (1998) Audiences: A Sociological Theory of Performance and Imagination, London: Sage

Althusser, L. (2008) On Ideology, London: Verso

De Certeau, M. (1984) The Practice of Everyday Life University of California Press. 
Dena, C. (2008) 'Emerging Participatory Culture Practices: Player-Created Tiers in Alternate Reality Games', Convergence: The International Journal of Research into New Media Technologies, 14, 41-57

Hall, S. (1973) Encoding and Decoding in the Television Discourse, Media Series, stencilled paper no. 7, Birmingham Centre for Contemporary Cultural Studies, The University of Birmingham Hall, S. (2007 [1973]) 'Encoding/Decoding' in S. During (ed.) The Cultural Studies Reader, 3rd ed., London: Routledge, pp. 90-103

Hall, S., Critcher C., Jefferson T., Clarke, J. N., and Roberts, B. (1978) Policing the Crisis: Mugging, the State, and Law and Order, London: Macmillan

Hall, S. and Jefferson, T. (eds) (1976) Resistance through Rituals: Youth Subcultures in Post-War Britain. Set Books. London: Hutchinson for the Centre for Contemporary Cultural Studies, University of Birmingham

Hebdige, D. (1979) Subculture: The Meaning of Style, London: Methuen

Hills, M. (2002) Fan Cultures, London; New York: Routledge

Jenkins, H. (1992) Textual Poachers: Television Fans and Participatory Culture, New York; London: Routledge

--- (2006a) Convergence Culture: Where Old and New Media Collide. New York; London: New York University Press

--- (2006b) Fans, Bloggers, and Gamers: Exploring Participatory Culture, New York: New York University Press

--- (2007) 'Afterword: The Future of Fandom', in J. Gray, C. Sandvoss and C. L. Harrington (eds) Fandom: Identities and Communities in a Mediated World, New York; London: New York University Press, pp. 357-364

Jenkins, H. Ford, S. and Green, J. (2013) Spreadable Media: Creating Value and Meaning in a Networked Culture, New York; London: Routledge; New York University Press

Kim, Y. J. Allen, J. P. Lee, E. (2008) 'Alternate Reality Gaming', Communications of the ACM, 51(2), 36-42

Levy, P. (1997) Collective Intelligence: Mankind's Emerging World in Cyberspace, New York; London: Plenum Trade

McGonigal, J. (2011) Reality is Broken: Why Games Make Us Better and How They Can Change the World, New York: Penguin Press

--- (2008) 'Why I Love Bees: A Case Study in Collective Intelligence Gaming', in K. Salen (ed.), The Ecology of Games: Connecting Youth, Games, and Learning, Cambridge, MA: MIT Press, pp. 199-228

Murray, S. (2004) “"Celebrating the Story the Way it is": Cultural Studies, Corporate Media and the Contested Utility of Fandom', Continuum: Journal of Media \& Cultural Studies, 18(1), 7-25

Stewart, S. (2012) personal interview with author, London, 17 October

Whiteman, N. (2009) 'The De/Stabilization of Identity in Online Fan Communities' Convergence: The International Journal of Research into New Media Technologies 15(4), 391-410 


\section{Web Sources}

42 Entertainment, website. Accessible at www.42entertainment.com. Accessed 12 October 2010 ARGFest Transcript 03 - Developing ARGS (2007). Accessible at http://wiki.argfestocon.com/index.php?title=2007vt03_Transcription. Accessed on 12 October 2013 ARGFest Transcript 04 - Running ARGS (2007). Accessible at http://wiki.argfestocon.com/index.php?title $=2007 \mathrm{vt} 03$ Transcriptionhttp://wiki.argfestocon.com/in dex.php?title=2007vt04_Transcription. Accessed on 12 October 2013

ARGFest Transcript 05 - Roundtable, 42 Entertainment - Development Process (2007). Accessible http://wiki.argfestocon.com/index.php?title=2007vt05 Transcription. Accessed 13 October 2013

Cloudmakers (2001), Post-Game Puppetmaster Chat 31 July 2001, Yahoo.com. Accessible at http://groups.yahoo.com/neo/groups/cloudmakers/files. Accessed 13 October 2013. Reproduced with kind permission of Cloudmakers Moderators.

Goldie, L. (2008) 'Copycat Warning Over Alternate Reality Games', NMA, 9 October. Accessible at http://econsultancy.com/uk/nma-archive/37656-alternate-reality-games. Accessed 12 October 2013

Hon, A. (2001) 'The Guide', Cloudmakers.org. Accessible at http://www.cloudmakers.org/guide/index5.shtml\#2.8. Accessed 12 October 2013

Lee, C. (2008) 'Bat Infiltration', Los Angeles Times, 24 March. Accessible at http://articles.latimes.com/2008/mar/24/entertainment/et-batmanviral24. Accessed 12 October 2013.

McGonigal, J. (2007) The Puppet Master Problem: Design for Real-World, Mission Based Gaming, blog post. Accessible at http://janemcgonigal.files.wordpress.com/2010/12/mcgonigal_the-puppetmaster-problem mitpress.pdf. Accessed 13 October 2013

Phillips A. (2005) Soapbox: ARGs and how to Appeal to Female Gamers, Gamasutra.com, 29 November. Accessible at http://www.gamasutra.com/view/feature/2471/soapbox_args and how to appeal to .php. Accessed 12 October 2013

Player Survey (2013), online survey conducted by author, April

Puppetmaster FAQ (2001) Cloudmakers.org. Accessible at http://familiasallaes.cloudmakers.org/credits/note/faq.html. Accessed 12 October 2013

Rose, F. (2007) 'Secret Websites, Coded Messages: The New World of Immersive Games' Wired, 16(1), 20 December, [online]. Accessible at http://www.wired.com/entertainment/music/magazine/16-01/ff_args. Accessed 12 October 2013

Ruberg, B. (2006) Elan Lee's Alternate Reality, Gamasutra.com. Accessible at http://www.gamasutra.com/view/feature/130182/elan_lees_alternate_reality.php?print=1. Accessed 12 October 2013

Siegel, S. J. (2006) Joystiq Interviews Elan Lee of 42 Entertainment, Joystiq.com, 14 November. Accessible at http://www.joystiq.com/2006/11/14/joystiq-interviews-elan-lee-of-42-entertainment/. Accessed 12 October 2013

Thompson, B. (2005) This is Not a Game and The TINAG Philosophy, ARGN.com, 27 April. Accessible at http://www.argn.com/2005/04/this_is_not_a_game/. Accessed 11 January 2014 